\title{
The Effect of Tai Chi on Quality of Life in Centrally Obese Adults with Depression
}

\author{
Xin Liu, $\mathrm{PhD}^{1-3}$ Gail Williams, $\mathrm{PhD}^{4}$ Karam Kostner, $\mathrm{MD}^{3,5}$ and Wendy J. Brown, $\mathrm{PhD}^{6}$
}

\begin{abstract}
Objectives: The aim of this pilot study was to assess the effects of a Tai Chi program on health-related quality of life (HR-QOL) in centrally obese adults with depression.

Methods: Two hundred thirteen participants were randomly allocated to either a Tai Chi intervention group $(n=106)$ or a usual medical care control group $(n=107)$. The Tai Chi group involved $3 \times 1.5 \mathrm{~h}$ supervised and group-based training sessions per week for 24 weeks. Indicators of HR-QOL were assessed by questionnaire at baseline, 12 weeks, and 24 weeks.

Results: There were significant improvements in favor of the Tai Chi group for the SF-36 subscales of physical functioning $(p<0.01)$, role physical $(p<0.01)$, and role emotional $(p<0.01)$ at 12 and 24 weeks. Scores for bodily pain were improved in the control group at 12 weeks $(p<0.01)$ and 24 weeks $(p<0.05)$, but not in the Tai Chi group. There was also a significant improvement in favor of the control group in general health $(p<0.05)$ at 12 weeks, but not at 24 weeks. A further analysis showed clinically significant changes in favor of the Tai Chi group in physical functioning $(p<0.05$ or $p=0.05)$, role physical $(p<0.05)$, and role emotional $(p<0.05)$, and in favor of the control group in bodily pain $(p<0.05)$ at 12 and 24 weeks.

Conclusions: The findings show that Tai Chi exercise improved indicators of HR-QOL including physical functioning, role physical, and role emotional in centrally obese adults with depression.
\end{abstract}

Keywords: Tai Chi, exercise, quality of life, central obesity, depression

\section{Introduction}

$\mathbf{T}$ Here Is GROWING evidence to suggest that Tai Chi may improve depressive symptoms and health-related quality of life (HR-QOL) in people with depression. ${ }^{1,2}$ However, no previous studies have reported the effects of Tai Chi on HRQOL in centrally obese adults with depression. Central obesity, a necessary requirement for defining metabolic syndrome ${ }^{3}$ and a high risk factor for developing cardiovascular diseases, ${ }^{4}$ is associated with depression, which has also been linked to increased risk of cardiovascular diseases. ${ }^{5,6}$ The aim of this study was to evaluate the effects of a Tai Chi-based program on HRQOL in this group.

\section{Methods}

Study design, participants, and intervention

This was a randomized controlled trial. This study was approved by the Human Research Ethics Committees of the Princess Alexandra Hospital, in Brisbane, Australia (2009/ 089) and the University of Queensland (2009001092). Written informed consent to participation was obtained before baseline assessment. Participants were recruited by general practitioners (GPs) and local media. Of the 536 prospective subjects who were screened for eligibility, 213 participants (1) with depression (diagnosed by GPs); (2) with central obesity (defined by the International Diabetes Federation

\footnotetext{
${ }^{1}$ School of Life Sciences, Beijing University of Chinese Medicine, Beijing, China.

${ }^{2}$ School of Wushu, Wuhan Sport University, Wuhan, China.

${ }^{3}$ The University of Queensland School of Medicine, Brisbane, Australia.

${ }^{4}$ The University of Queensland School of Public Health, Brisbane, Australia.

${ }^{5}$ Department of Cardiology, Mater Health Services, Brisbane, Australia.

${ }^{6}$ The University of Queensland School of Human Movement and Nutrition Sciences, Brisbane, Australia.
} 
[waist circumference $>95 \mathrm{~cm}$ for men; $80 \mathrm{~cm}$ for women, and/or body mass index $\left.\left.>30 \mathrm{~kg} / \mathrm{m}^{2}\right]\right)^{3}$; and (3) who were taking antidepressants for depression or had a short form Center for Epidemiologic Studies Depression Scale 10 (CESD10) rating score of 10 or higher $^{7-9}$ were recruited. They were randomized to a Tai Chi intervention group $(n=106)$ or usual medical care control group $(n=107)$, by an independent researcher (using a computer-generated randomization schedule). The CES-D10 shows good predictive accuracy compared with the full-length 20-item version of the CESD20 (kappa $=0.97, p<0.001$ ) with a cutoff score for depression of 10 or more on the CES-D10. ${ }^{8}$

The Tai Chi intervention was a supervised group-based program with $3 \times 1.5 \mathrm{~h}$ training sessions per week for 24 weeks, which has been described in more detail elsewhere. ${ }^{10}$ All participants signed a consent form before baseline assessment and continued to receive usual medical care from their GPs during the study. Ethical approval for the study was obtained from The University of Queensland Human Research Ethics Committee (2009001092) and the Princess Alexandra Hospital, in Brisbane, Australia (2009/089).

\section{Measures}

Each participant completed a self-report survey at baseline, and 12 and 24 weeks postintervention. HR-QOL was assessed using the Medical Outcomes Study (MOS) SF-36 survey. ${ }^{11}$ The items assess eight dimensions: general health, physical functioning, role-physical, role-emotional, social functioning, bodily pain, mental health, and vitality. Scores ranged from 0 to 100, with higher scores representing better HR-QOL. The MOS SF-36 has been shown to be reliable and valid for Australian adults. ${ }^{12,13}$ The assessments were conducted by an independent research assistant who was blinded to group allocation and previous outcomes.

\section{Statistical analysis}

Baseline characteristics for Tai Chi intervention group and control group in HR-QOL measures were compared using $t$ tests. Mean changes and 95\% confidence intervals were calculated for each outcome measure, for changes from baseline to 12 and 24 weeks. One-sample $t$ tests were used to explore differences in mean measurements within the same group over time (this is equivalent to the paired $t$ test). General linear regression models were used to detect betweengroup differences in mean change scores from baseline to 12 and 24 weeks. General linear regression models repeated measures were used to detect the time $\times$ group interaction effects over the 6-month study. Clinically significant changes were identified, using cutoffs for selected parameters, ${ }^{14-16}$ and compared for the intervention and control groups, using chi-squared tests. Intention-to-treat methods were used for primary analyses. All statistical tests were two-sided with significance level $p<0.05$. All analyses were performed using SPSS.

\section{Results}

The flow of participants through the study has been reported previously. ${ }^{10}$ In brief, 213 participants were randomized to the intervention and control groups (Tai Chi intervention group $[n=106]$; usual medical care control group $[n=107])$. The baseline characteristics of the participants have been reported previously. ${ }^{10}$ In brief, they were aged 19-77 years (mean 52 \pm 12 years), more than two thirds were women and more than two thirds had two or more coexisting chronic conditions including depression, arthritis or rheumatism, diabetes, heart disease, hypertension, stroke, and lung disease. At baseline, based on the defined categories of severity levels of depression, the participants had moderately severe levels of depression. ${ }^{10}$ The participants had lower than Australian national normative scores in people with depression ${ }^{17}$ in five SF-36 subscales at baseline, including physical functioning, rolephysical, role-emotional, social functioning, and bodily pain. There was no between-group difference in any of the HR-QOL measures at baseline (Table 1).

Mean changes and between-group differences in the SF36 subscales after the 12- and 24-week intervention are given in Table 2. There were statistically significant between-group differences in favor of the Tai Chi group in three of the SF-36 subscale measures, including physical functioning, role-physical, and role-emotional at 12 weeks $(p<0.001)$ and 24 weeks $(p<0.001)$. The mean differences ranged from 6.6 for physical functioning to 17.6 for role-emotional at 12 weeks; and from 8.0 for physical functioning to 20.5 for role-emotional at 24 weeks, after controlling for baseline values. Of importance, compared with the control group, there were also clinically significant improvements in the Tai Chi group (i.e., a change of 10 points or more) in physical functioning $(p<0.05$ or $p=0.05)$, role-physical $(p<0.05)$, and role-emotional $(p<0.05)$ at 12 and 24 weeks (Table 2$)$. In addition, there were statistically significant between-group differences in

Table 1. Quality of Life Measures at Baseline

\begin{tabular}{lccc}
\hline Measures & $\begin{array}{c}\text { Tai Chi }(\mathrm{n}=106), \\
\text { mean }(S D)\end{array}$ & $\begin{array}{c}\text { Control }(\mathrm{n}=107), \\
\text { mean }(S D)\end{array}$ & \begin{tabular}{c} 
Between-group difference \\
\cline { 3 - 4 }
\end{tabular} \\
SF-36 physical functioning & $70.2(21.4)$ & $69.7(20.2)$ & 0.870 \\
SF-36 role physical & $50.7(40.7)$ & $56.7(36.9)$ & 0.256 \\
SF-36 bodily pain & $30.2(22.0)$ & $31.4(20.1)$ & 0.676 \\
SF-36 general health & $61.5(11.6)$ & $61.4(12.4)$ & 0.925 \\
SF-36 vitality & $58.5(9.9)$ & $57.1(9.5)$ & 0.318 \\
SF-36 social functioning & $50.4(10.6)$ & $50.1(10.7)$ & 0.809 \\
SF-36 role emotional & $35.8(37.5)$ & $31.1(34.0)$ & 0.340 \\
SF-36 mental health & $65.0(9.5)$ & $62.6(8.8)$ & 0.062 \\
\hline
\end{tabular}


Table 2. Changes in Outcomes During 6 Months Intervention

\begin{tabular}{|c|c|c|c|c|c|c|}
\hline \multirow[b]{2}{*}{ Variable } & \multirow[b]{2}{*}{ Comparison } & \multicolumn{2}{|c|}{$\begin{array}{c}\text { Within-group } \\
\text { difference }(95 \% \text { CI) }\end{array}$} & \multicolumn{2}{|c|}{$\begin{array}{c}\text { Between-group } \\
\text { difference }(95 \% \mathrm{CI})\end{array}$} & \multirow{2}{*}{$\begin{array}{c}\begin{array}{c}\text { Interaction } \\
\text { effects }\end{array} \\
\mathrm{p}^{\mathrm{b}}\end{array}$} \\
\hline & & $\begin{array}{c}\text { Tai Chi } \\
\text { group, } \mathrm{n}=106\end{array}$ & $\begin{array}{c}\text { Control group, } \\
\mathrm{n}=107\end{array}$ & $\begin{array}{l}\text { Tai Chi vs. } \\
\text { control group }\end{array}$ & $\mathrm{p}^{\mathrm{a}}$ & \\
\hline \multirow{2}{*}{$\begin{array}{l}\text { SF-36 physical } \\
\text { functioning }\end{array}$} & 3 months vs. baseline & $4.7(2.0$ to 7.4$)$ & $-1.8(-4.3$ to 0.6$)$ & $6.5(2.9$ to 10.2$)$ & $<0.01$ & \multirow[b]{2}{*}{$<0.01$} \\
\hline & 6 months vs. baseline & $4.3(1.2$ to 7.5$)$ & $-3.6(-6.8$ to -0.3$)$ & $7.9(3.4$ to 12.4$)$ & $<0.01$ & \\
\hline \multirow{2}{*}{$\begin{array}{l}\text { SF-36 role } \\
\text { physical }\end{array}$} & 3 months vs. baseline & $9.0(1.4$ to 16.5$)$ & $-10.5(-17.8$ to -3.2$)$ & $19.5(9.0$ to 29.9$)$ & $<0.01$ & \multirow{2}{*}{$<0.01$} \\
\hline & 6 months vs. baseline & $14.8(7.8$ to 21.9$)$ & $-4.0(-12.0$ to 4.0$)$ & $18.8(8.2$ to 29.4$)$ & $<0.01$ & \\
\hline \multirow{2}{*}{$\begin{array}{l}\text { SF-36 bodily } \\
\text { pain }\end{array}$} & 3 months vs. baseline & $-2.7(-5.7$ to 0.3$)$ & $6.1(2.6$ to 9.6$)$ & $-8.8(-13.4$ to -4.2$)$ & $<0.01$ & \multirow[b]{2}{*}{$<0.01$} \\
\hline & 6 months vs. baseline & $0.2(-3.4$ to 3.8$)$ & $5.5(2.3$ to 8.7$)$ & $-5.3(-10.1$ to -0.6$)$ & $<0.05$ & \\
\hline \multirow{2}{*}{$\begin{array}{l}\text { SF-36 general } \\
\text { health }\end{array}$} & 3 months vs. baseline & $-2.9(-4.8$ to -1.0$)$ & $-0.1(-2.0$ to 1.7$)$ & $-2.8(-5.4$ to -0.2$)$ & $<0.05$ & \multirow{3}{*}{0.10} \\
\hline & 6 months vs. baseline & $-3.2(-5.1$ to -1.3$)$ & $-1.9(-3.8$ to 0.1$)$ & $-1.3(-4.0$ to 1.3$)$ & 0.32 & \\
\hline \multirow[t]{2}{*}{ SF-36 vitality } & 3 months vs. baseline & $0.2(-1.7$ to 2.2$)$ & $0.8(-1.1$ to 2.7$)$ & $-0.6(-3.3$ to 2.2$)$ & 0.69 & \\
\hline & 6 months vs. baseline & $-0.0(-2.0$ to 1.9$)$ & $1.0(-1.0$ to 3.0$)$ & $-1.0(-3.8$ to 1.7$)$ & 0.46 & \multirow[t]{2}{*}{0.76} \\
\hline \multirow{2}{*}{$\begin{array}{l}\text { SF-36 social } \\
\text { functioning }\end{array}$} & 3 months vs. baseline & $0.1(-2.0$ to 2.3$)$ & $1.6(-0.8$ to 4.1$)$ & $-1.5(-4.8$ to 1.8$)$ & 0.36 & \\
\hline & 6 months vs. baseline & $0.2(-2.0$ to 2.4$)$ & $1.6(-0.9$ to 4.1$)$ & $-1.4(-4.7$ to 1.9$)$ & 0.41 & 0.62 \\
\hline \multirow{2}{*}{$\begin{array}{l}\text { SF-36 role } \\
\text { emotional }\end{array}$} & 3 months vs. baseline & $16.0(7.4$ to 24.7$)$ & $0.9(-5.7$ to 7.6$)$ & 15.1 (4.3 to 25.9$)$ & $<0.01$ & \multirow[b]{2}{*}{$<0.01$} \\
\hline & 6 months vs. baseline & $21.4(13.4$ to 29.3$)$ & $3.4(-4.3$ to 11.1$)$ & $18.0(7.0$ to 29.0$)$ & $<0.01$ & \\
\hline \multirow{2}{*}{$\begin{array}{l}\text { SF-36 mental } \\
\text { health }\end{array}$} & 3 months vs. baseline & $0.9(-0.6$ to 2.5$)$ & $1.7(-0.2$ to 3.7$)$ & $-0.8(-3.3$ to 1.7$)$ & 0.52 & \multirow[b]{2}{*}{0.45} \\
\hline & 6 months vs. baseline & $0.4(-1.0$ to 1.8$)$ & $1.9(0.0$ to 3.9$)$ & $-1.5(-3.9$ to 0.8$)$ & 0.21 & \\
\hline
\end{tabular}

favor of the control group in bodily pain at 12 weeks $(p<0.01)$ and 24 weeks $(p<0.05)$, and general health at 12 weeks $(p<0.05)$. The mean difference ranged from 9.2 for bodily pain to 2.7 at 12 weeks for general health, after controlling for baseline values. There were also clinically significant improvements in favor of the control group in bodily pain $(p<0.05)$ at 12 and 24 weeks (Table 3$)$. Scores for bodily pain were improved in the control group at 12 weeks $(p<0.01)$ and 24 weeks $(p<0.05)$, but not in the Tai Chi group (Table 2).

Statistically significant interaction effects over the 6 months were found in physical functioning $(p<0.01)$, role- physical $(p<0.01)$, bodily pain $(p<0.01)$, and roleemotional $(p<0.01)$, but not in general health, vitality, social functioning, and mental health (Table 2).

\section{Discussion}

This was the first study to evaluate the effects of a Tai Chi program on HR-QOL in centrally obese people with depression. In this study, there were significant improvements in three of the SF-36 subscale scores, including physical functioning, role-physical, and role-emotional, in the Tai Chi intervention group, relative to the control group, after both

Table 3. Patients with Clinically Significant Improvements During 6-Month Intervention

\begin{tabular}{|c|c|c|c|c|}
\hline Variables & & $\begin{array}{l}\text { Tai Chi group } \\
(\mathrm{n}=107), \mathrm{n}(\%)^{\mathrm{a}}\end{array}$ & $\begin{array}{l}\text { Control group } \\
(\mathrm{n}=106), \mathrm{n}(\%)^{\mathrm{a}}\end{array}$ & $\begin{array}{c}\mathrm{p} \text { for between-group } \\
\text { difference }\end{array}$ \\
\hline \multirow[t]{2}{*}{ SF-36 physical functioning ${ }^{c}$} & 3 months vs. baseline & $29(27)$ & $15(14)$ & 0.02 \\
\hline & 6 months vs. baseline & $33(31)$ & $20(18)$ & 0.05 \\
\hline \multirow[t]{2}{*}{ SF-36 physical role ${ }^{c}$} & 3 months vs. baseline & $34(32)$ & 17 (16) & 0.01 \\
\hline & 6 months vs. baseline & $40(38)$ & $22(21)$ & 0.01 \\
\hline \multirow[t]{2}{*}{ SF-36 bodily pain } & 3 months vs. baseline & $21(20)$ & $43(40)$ & 0.01 \\
\hline & 6 months vs. baseline & $29(27)$ & 47 (44) & 0.02 \\
\hline \multirow[t]{2}{*}{ SF-36 general health } & 3 months vs. baseline & $9(9)$ & $20(19)$ & 0.05 \\
\hline & 6 months vs. baseline & $10(9)$ & $14(13)$ & 0.53 \\
\hline \multirow[t]{2}{*}{ SF-36 vitality } & 3 months vs. baseline & 17 (16) & $15(14)$ & 0.83 \\
\hline & 6 months vs. baseline & $16(15)$ & $19(18)$ & 0.73 \\
\hline \multirow[t]{2}{*}{ SF-36 social functioning } & 3 months vs. baseline & $24(23)$ & $30(28)$ & 0.46 \\
\hline & 6 months vs. baseline & $22(21)$ & $33(31)$ & 0.13 \\
\hline \multirow[t]{2}{*}{ SF-36 emotional role ${ }^{c}$} & 3 months vs. baseline & $35(33)$ & $24(22)$ & 0.12 \\
\hline & 6 months vs. baseline & $44(42)$ & $27(25)$ & 0.02 \\
\hline \multirow[t]{2}{*}{ SF-36 mental health } & 3 months vs. baseline & $12(11)$ & 19 (18) & 0.26 \\
\hline & 6 months vs. baseline & 12 (11) & 18 (17) & 0.34 \\
\hline
\end{tabular}

${ }^{\mathrm{a}}$ Values were calculated with intention-to-treat analyses.

${ }_{p}^{b}$-Values were calculated using the chi-squared test.
${ }^{\mathrm{A}} \mathrm{A}$ change of 10 points or more on the SF-36 subscales indicates clinically significant change. ${ }^{14-16}$ 
12 and 24 weeks of intervention. The intervention group participants also anecdotally reported these improvements when being asked about perceived benefits. This is consistent with the work by Lavretsky et al. who also found improvements in physical functioning and mental health (depression symptoms) after a 10-week Tai Chi intervention for people with geriatric depression. ${ }^{1}$

In this study, more than two thirds of participants in both groups reported a range of chronic health problems (arthritis or rheumatism, diabetes, heart disease, hypertension, stroke, and lung disease). This reflects the poor overall health status of this clinical group. The improvements in both role-physical/ physical functioning and role-emotional are therefore important for this challenging group. Compared with other more vigorous forms of exercise, Tai Chi could be offered as an alternative to achieve these improvements and may play a role in helping people to become physically and mentally well.

The key strengths of this study are the randomized controlled design and the prolonged intervention. The authors also acknowledge that the findings were not based on a specific clinical category of depression (such as major depression disorder). The findings are however relevant to the population of patients with depression symptoms usually seen in primary care.

\section{Conclusions}

In conclusion, the findings from this study suggest that Tai Chi exercise may improve some physical and emotional indicators of HR-QOL in centrally obese people with depression. Larger controlled trials are required to further confirm the findings.

\section{Acknowledgments}

The authors thank Diabetes Queensland for assistance in recruiting participants, and Princess Alexandra Hospital, St. Philip's Anglican Church, Anglican Parish of Indooroopilly, and Saint Andrew's Uniting Church in Brisbane for providing exercise venues for the study. The authors especially acknowledge the study participants. Trial registration: Australian New Zealand Clinical Trials Registry: ACTRN12613000010796.

\section{Author Disclosure Statement}

No competing financial interests exist.

\section{Funding Information}

This study was supported by a joint grant from the Australian National Heart Foundation and the national depression initiative, beyondblue (G 088 4034).

\section{References}

1. Lavretsky H, Alstein LL, Olmstead RE, et al. Complementary use of tai chi chih augments escitalopram treatment of geriatric depression: A randomized controlled trial. Am J Geriatr Psychiatry 2011;19:839-850.

2. Chou KL, Lee PW, Yu EC, et al. Effect of Tai Chi on depressive symptoms amongst Chinese older patients with depressive disorders: A randomized clinical trial. Int $\mathbf{J}$ Geriatr Psychiatry 2004;19:1105-1107.

3. International Diabetes Federation Western Pacific Region and the Asian-Pacific Type 2 Diabetes Policy
Group. Type 2 Diabetes: Practical Targets and Treatments, 4th ed. Melbourne: The International Diabetes Institute, 2005:43-44.

4. Yusuf S, Hawken S, Ounpuu S, et al. Effect of potentially modifiable risk factors associated with myocardial infarction in 52 countries (the INTERHEART study): Casecontrol study. Lancet 2004;364:937-952.

5. van ReedtDortland AK, Giltay EJ, van Veen T, et al. Longitudinal relationship of depressive and anxiety symptoms with dyslipidemia and abdominal obesity. Psychosom Med 2013;75:83-89.

6. Needham B, Epel E, Adler N, Kiefe C. Trajectories of change in obesity and symptoms of depression: The CARDIA study. Am J Public Health 2010;100:1040.

7. Radloff LS. The CES-D scale: A self-report depression scale for research in the general population. Appl Psychol Meas 1977;1:385-401.

8. Andresen EM, Malmgren JA, Carter WB, et al. Screening for depression in well older adults: Evaluation of a short form of the CES-D (Center for Epidemiologic Studies Depression Scale). Am J Prev Med 1994;10:77-84.

9. Murphy JM. Symptom scales and diagnostic schedules in adult psychiatry. In: Tsuang MT, Tohen M, eds. Textbook in Psychiatric Epidemiology. New York: Wiley-Liss, 2002:273-332.

10. Liu X, Vitetta L, Kostner K, et al. The effects of Tai Chi in centrally obese adults with depression symptoms. Evid Based Complement Alternat Med 2015;2015:879712.

11. Ware J, Snow K, Kosinski M. SF-36 Health Survey: Manual and Interpretation Guide. Lincoln: QualityMetric, Inc.; Boston: The Health Assessment Lab, 2000.

12. Lin M, Ward JE. Reliability of the MOS SF-36 health status measure in Australian general practice. Aust Fam Physician 1998;27(Suppl 2):S94-S98.

13. Bensoussan A, Chang SW, Menzies RG, Talley NJ. Application of the general health status questionnaire SF-36 to patients with gastrointestinal dysfunction: Initial validation and validation as a measure of change. Aust NZ J Public Health 2001;25:71-77.

14. Samsa G, Edelman D, Rothman ML, et al. Determining clinically important differences in health status measures a general approach with illustration to the Health Utilities Index Mark II. Pharmacoeconomics 1999;15:141-155.

15. Bize R, Johnson JA, Plotnikoff RC. Physical activity level and health-related quality of life in the general adult population: A systematic review. Prev Med 2007;45:401-415.

16. Amberley B, Roxanne MP, Daisy G, et al. Defining the minimally clinically important difference of the SF-36 physical function subscale for paediatric CFS/ME: Triangulation using three different methods. Health Qual Life Outcomes 2018;16:202.

17. Australian Bureau of Statistics. National Health Survey: SF-36 Population Norms. Canberra: ABS, 1995.

Address correspondence to: Xin Liu, PhD

School of Life Sciences Beijing University of Chinese Medicine 808 YiFu Research Building No. 11, Bei San Huan Dong Road ChaoYang District Beijing 100029 China

E-mail: xin.liu@uqconnect.edu.au 